\title{
La aplicación de la prescripción gradual del delito en las causas sobre violaciones de derechos humanos*
}

Este comentario, junto a los documentos que analiza, está disponible en www.anuariocdh.uchile.cl
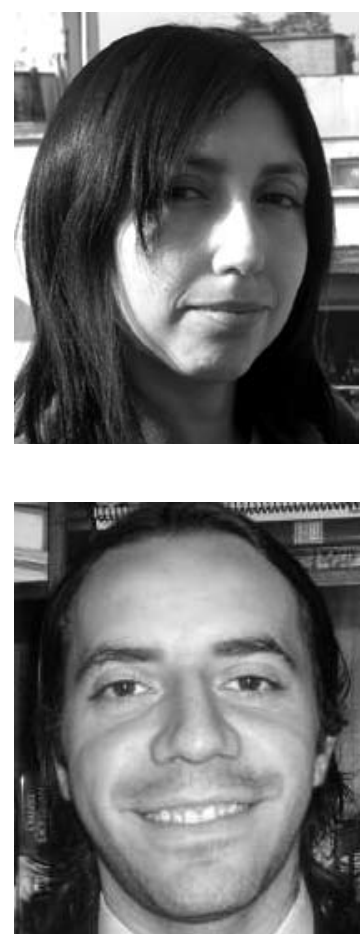

\section{Karinna Fernández Neira}

Licenciada en ciencias jurídicas de la Universidad de Valparaíso, actualmente cursa el Magíster de Derecho de la Universidad de Chile. Abogada del Programa de Derechos Humanos del Ministerio de Interior.

kfernandez@interior.gov.cl

\section{Prietro Sferrazza Taibi}

Licenciado en ciencias jurídicas Universidad de Valparaíso, asesor parlamentario Cámara de Diputados del Congreso Nacional.

prietrosferrazza@yahoo.es

\section{RESUMEN}

Mediante el análisis de dos sentencias dictadas por la Corte Suprema durante el año 2008, los autores analizan críticamente la tendencia jurisprudencial de dicho tribunal de aplicar la prescripción gradual en casos instruidos por graves violaciones a los derechos humanos. Tras una exposición del contenido de las sentencias, se enfrentan críticamente los argumentos que sostienen la aplicación de un instituto que ha permitido al máximo tribunal otorgar la libertad vigilada a sujetos responsables de la comisión de delitos de lesa humanidad. Finalmente, se contrasta lo resuelto por la Corte Suprema con las obligaciones internacionales del Estado de Chile en materia de derechos humanos.

* Queremos agradecer al Dr. José Luis Guzmán Dálbora y al Dr. Hernán Quezada Cabrera por sus valiosos consejos, sugerencias bibliográficas y colaboración en el esclarecimiento de ciertos problemas conceptuales. 
Desde hace aproximadamente dos años la Corte Suprema comenzó a aplicar en los casos de derechos humanos ${ }^{1}$ la prescripción gradual o media prescripción, regulada en el artículo 103 del Código Penal ${ }^{2}$. Los argumentos con los que nuestro máximo tribunal ha justificado su procedencia presentan una serie de fricciones y ligerezas dogmáticas e interpretativas que requieren de una reflexión. Para estos efectos, comentaremos las sentencias recaídas en los procesos denominados "Episodio Parral" y "Episodio Liquiñe", ambos por secuestros calificados, en las que se aplicó la prescripción gradual. La elección de estas resoluciones y no de otras responde a la significación de los "episodios" aludidos, por el gran número de víctimas involucradas y a la similar estructura argumentativa adoptada en ambas sentencias.

En primer lugar, haremos una breve reseña de los procesos, refiriéndonos a las sentencias definitivas de primera y segunda instancia y luego a las resoluciones dictadas por la Corte Suprema. En la segunda, expondremos críticamente los aspectos dogmáticos más discutibles.

\section{Síntesis de la jurisprudencia en análisis: antecedentes procesales y principales puntos resolutivos}

\section{a. Episodio Parral}

En el denominado "Episodio Parral" -causa instruida por el ministro de fuero Alejandro Solís Muñoz- se condenó en primera instancia ${ }^{3}$ a diecisiete años de presidio mayor en su grado máximo a Hugo Cardemil Valenzuela; diez años y un día de presidio mayor en grado máximo a Pablo Caulier Grant y siete años de presidio mayor en su grado mínimo a Luis Alberto Hidalgo, todas con penas accesorias y condena en costas. Estas penas se impusieron por estimarse acreditadas las responsabilidades de los condenados en los delitos de secuestros calificados cometidos en contra de veintiséis campesinos, un joven estudiante de medicina y en la sustracción de un menor de edad en la localidad de Parral. Se consideró que estos delitos eran de consumación permanente, se declaró su imprescriptibilidad y la inaplicabilidad de la ley de amnistía ${ }^{4}$.

Conociendo de un recurso de apelación, la Corte de Apelaciones de Santiago ${ }^{5}$ elevó la pena impuesta al sentenciado Luis Alberto Hidalgo a diez años y un día de presidio mayor en su grado medio, y redujo la pena aplicada al condenado Hugo Cardemil Valenzuela a quince años y un día de presidio mayor en su grado medio.

1 Según fuentes del Programa Continuación Ley 19.123, del Ministerio del Interior, desde el 30 de julio de 2007, fecha en que la Corte Suprema concedió la prescripción gradual a los responsables del secuestro de Juan Luis Rivera Matus, el máximo tribunal ha dictado 25 sentencias en casos sobre violaciones a los derechos humanos, de las cuales 3 han declarado aplicable la prescripción y 15 , la prescripción gradual.

2 Para la evolución de la jurisprudencia sobre violaciones a los derechos humanos, cfr. BONARD, R. y SFERRAZZA, P. El sistema judicial y la justicia penal desde 1998. En: Seminario El "Efecto Pinochet" a 10 años de Londres 1998 (octubre 2008), Santiago, Universidad Diego Portales; GUZMÁN DÁLBORA, J. L. Chile. En AMBOS, K. y MALARINO, E. (Eds.): Jurisprudencia latinoamericana sobre Derecho Penal Internacional. Montevideo, Konrad Adenauer Stiftung, 2008, pp. 131-158; en relación a la prescripción gradual, FERNÁNDEZ NEIRA, K. y SFERRAZZA, P. La aplicación de la Prescripción Gradual en casos de Violaciones a los Derechos Humanos. [En línea]. Asociación pensamiento penal. <http://www.pensamientopenal.com.ar/16102008/doctrina03.pdf> [Consulta: 18 enero 2009].

3 Resolución de 4 agosto 2003, proceso Rol № 2182-98.

4 Considerando 76.

5 En sentencia de 15 junio de 2008, dictada en proceso Rol № 3587-05, por los ministros Juan Manuel Muñoz Pardo, Alejandro Madrid Croharé y Humberto Provoste Bachmann, este último en calidad de suplente. 
La Corte Suprema ${ }^{6}$, resolviendo un recurso de casación, invalidó de oficio la sentencia por considerar que adolecía de vicios formales, toda vez que no se había referido a la prescripción gradual alegada por la defensa de los condenados. Posteriormente dictó una sentencia de reemplazo y declaró que los delitos, no obstante ser imprescriptibles, se encontraban gradualmente prescritos por aplicación del artículo 103 del Código Penal. Debido a ello, Hugo Cardemil Valenzuela quedó condenado a cinco años de presidio menor en su grado máximo; Pablo Caulier Grant, a cuatro años de presidio menor en su grado máximo, y Luis Alberto Hidalgo fue sobreseído tras su fallecimiento. El fallo, adicionalmente, atendida la baja cuantía de las penas, concedió el beneficio de libertad vigilada a los condenados, sin que ninguno de ellos fuere privado de libertad.

En síntesis, la sentencia de reemplazo señala que:

(i) Se consideró que los delitos cometidos eran imprescriptibles, pues el contexto social imperante en Chile a la fecha de la comisión de los ilícitos hacía aplicables las Convenciones de Ginebra, particularmente lo dispuesto en el artículo $3^{\circ}$ común, relativo al "conflicto armado sin carácter de internacional". Para estos efectos, el tribunal invoca los Decretos Leyes números 3 y 5 de 1973, que se refieren a la existencia de un "estado o tiempo de guerra" en el país, y los Decretos Leyes números 640 y 641 de 1974, que hablan de "estado de sitio en grado de defensa interna"7.

(ii) Sin perjuicio de lo anterior, la Corte no encuentra inconvenientes técnicos para hacer aplicable la prescripción gradual. En efecto, si bien esta última presenta características comunes con la prescripción, tales como el hecho de estar ubicadas sistemáticamente en el mismo título del Código $^{8}$ y, la más importante, el hecho de tener su fundamento último en el transcurso del tiempo, se planteó que dichas instituciones se proyectan hacia objetivos disímiles: la prescripción extingue la responsabilidad penal, mientras la prescripción gradual atenúa la pena. Por tanto, la Corte concluye que la prescripción gradual es una circunstancia modificatoria de la responsabilidad penal de aquellas que disminuyen o atenúan la pena, teniendo, por ende, una naturaleza jurídica diferente de la prescripción. Es por eso que la Corte entiende que la imprescriptibilidad dimanante del Derecho internacional no configura una autolimitación estatal para la aplicación de la prescripción gradual ${ }^{9}$.

(iii) La Corte califica el secuestro como un delito de consumación permanente. Una de las implicancias técnicas de un delito con estas características se relaciona con el parámetro para computar el plazo de prescripción o prescripción gradual, ya que el inicio del mismo coincide con el cese de la lesión del bien jurídico. Como se trata de secuestro calificado, el sentenciador entendió que el delito se ha consumado al prolongarse la privación de libertad por más de noventa días, contando el inicio del plazo a partir del día noventa y $\operatorname{dos}^{10}$.

6 En sentencia de 27 diciembre 2007, recaída en proceso Rol № 3.587-05, pronunciado por la segunda sala, integrada por los ministros Nibaldo Segura, Jaime Rodríguez, Rubén Ballesteros, Hugo Dolmestch y el abogado integrante Juan Carlos Cárcamo.

7 Considerandos $14^{\circ}$ al $17^{\circ}$.

8 Título $V$ del libro I, "De la extinción de la responsabilidad penal".

9 Considerandos $18^{\circ}$ al $26^{\circ}$. Cabe hacer referencia a la prevención de los siguientes ministros: Rodríguez Espoz, quien estuvo por no aplicar la prescripción gradual y mantener las condenas de primera instancia; Segura, quien estimó que no resulta posible considerar las circunstancias temporales como fundamento para la aplicación de la prescripción gradual, en desprecio del reconocimiento de la prescripción plena y Ballesteros, quien, pese a su opinión de absolver por la vía de la prescripción de la acción penal, comparte el criterio de que a los encausados favorece la prescripción gradual como atenuante.

10 Considerando $26^{\circ}$. 


\section{b. Episodio Liquiñe}

En el denominado "Episodio Liquiñe" ${ }^{11}$, causa también instruida por el ministro en visita Alejandro Solís Muñoz, se condenó en primera instancia a Hugo Alberto Guerra Jorquera a 18 años de presidio mayor en su grado máximo, por los secuestros calificados de once personas, y a Luis García Arán a 5 años y un día de presidio mayor en grado mínimo, por el secuestro calificado de Luis Lagos Torres, más penas accesorias y condenas en costas. Estos delitos -perpetrados a partir del 10 de octubre de 1973- se declararon imprescriptibles e inamnistiables, en base a su carácter de ejecución permanente y por aplicación de lo dispuesto en los Convenios de Ginebra ${ }^{12}$. En segunda instancia el fallo fue confirmado en todas sus partes por la Corte de Apelaciones de Santiago ${ }^{13}$.

La Corte Suprema ${ }^{14}$, de manera similar a lo resuelto en el "Episodio Parral", al conocer un recurso de casación en el fondo, invalidó de oficio la sentencia recurrida. Las consecuencias también fueron las mismas: dictó sentencia de reemplazo y, pese a considerar imprescriptibles los delitos, aplicó la prescripción gradual, rebajando la condena de Hugo Guerra Jorquera a 5 años de presidio menor en su grado máximo y la de Luis García Arán, a 3 años y un día de presidio menor en su grado máximo, concediéndoles a ambos el beneficio de libertad vigilada.

Este fallo de reemplazo se sustenta en argumentos similares a los reproducidos en las letras (i) ${ }^{15}$, (ii) $^{16}$ y (iii) ${ }^{17}$ precedentes, pero con matices relevantes. Respecto de la imprescriptibilidad de los delitos, además de las Convenciones de Ginebra, la Corte alude a las normas de ius cogens ${ }^{18}$. En cuanto a la determinación del inicio del plazo de la prescripción gradual, calificando al teniente coronel Guerra como autor mediato por dominio de la voluntad mediante aparato organizado de poder, el sentenciador concluye que la fecha a partir de la cual debe contabilizarse es aquella en que se acogió a retiro de la institución castrense, porque la Corte entiende que ese es el momento en que el condenado aludido perdió definitivamente el dominio del hecho por serle imposible mantener a las víctimas privadas de libertad ${ }^{19}$ y porque han transcurrido más de 18 años desde la reinstalación de la normalidad democrática en Chile $^{20}$.

\section{Comentarios críticos}

Analizaremos tres problemas vinculados con la aplicación de la prescripción gradual en estas causas. El primero de ellos dice relación a la determinación del fundamento que inspira esta institución. El segundo se produce por ser el secuestro un delito permanente, ya que surgen ciertas dificultades para el cómputo del plazo de la prescripción gradual. En tercer lugar, haremos una

11 Resolución de 25 de enero 2006, recaída en proceso Rol № 2182-98.

12 Considerandos $24^{\circ}$ al $28^{\circ}$.

13 Sentencia de 1 agosto de 2007, dictada en proceso Rol № 2136-06, por los ministros Juan González Zúñiga, Dobra Lusic Nadal y por el abogado integrante Eduardo Morales Robles.

14 Sentencia de 25 septiembre de 2008, dictada en proceso Rol № 4662-07, pronunciada por la segunda sala, integrada por los ministros Nibaldo Segura, Hugo Dolmestch, Carlos Künsemüller y los abogados integrantes Juan Carlos Cárcamo y Domingo Hernández.

15 Considerandos $5^{\circ}$ al $8^{\circ}$.

16 Considerandos $11^{\circ}$ al $18^{\circ}$. Al respecto, digno de interés es el voto de prevención del ministro Carlos Künsemüller quien estuvo por rechazar la solicitud de prescripción gradual.

17 Considerandos $19^{\circ}$ al $23^{\circ}$.

18 Último párrafo del considerando $8^{\circ}$.

19 Considerandos $20^{\circ}, 21^{\circ}$ y $22^{\circ}$.

20 Considerando $23^{\circ}$. 
síntesis de las obligaciones internacionales que el Estado de Chile infringe al aplicar la prescripción gradual en estos casos.

\section{a. Fundamento de la prescripción gradual}

La identificación del fundamento de la prescripción es uno de los temas que más ha atormentado a la doctrina penal y procesal penal, siendo muchas las teorías que han tratado de dilucidar dicho problema ${ }^{21}$. Acotándonos a los límites de este trabajo, intentaremos esclarecer si la prescripción gradual posee los mismos fundamentos de la prescripción, para luego dilucidar las consecuencias jurídicas que deriven de dicha respuesta22.

Compartimos la tesis de que "[l]a prescripción gradual de la acción penal y de la pena [...] hinca su fundamento en las mismas consideraciones de estabilización social y seguridad jurídica [de la prescripción] y se hace cargo de que a la realización de esas aspiraciones no se llega con un golpe fulminante, sino al cabo de un proceso gradual" 23 . Ambas instituciones comparten un punto de partida: el transcurso del tiempo, el cual justifica y motiva la estructuración dogmática de estos conceptos. Así, las normas que contemplan la prescripción gradual no son sino un reflejo de las normas reguladoras de la prescripción: parten del mismo supuesto, comparten la misma naturaleza, participan de los mismos fundamentos y ubicación sistemática en el Código Penal. Luego, la prescripción gradual configura una regla de aplicación de la prescripción, al igual que otras reglas que se encargan de normar el plexo de sus aspectos. Además, un buen argumento para reforzar la similitud de naturaleza de estas instituciones, es la existencia de normas que les son aplicables a ambas, como las que regulan sus causales de interrupción y de suspensión. Atendido lo dicho, los considerandos de los fallos en análisis que desestiman la importancia de la sistematización de la institución en comento carecen de rigor argumentativo, ya que la regla es que lo normado en un espacio dentro de la geografía del Código comparta características comunes con el resto de las instituciones objeto de regulación en ese mismo espacio ${ }^{24}$.

La diferencia evidente entre estos conceptos estriba en el efecto jurídico que generan y no en sus fundamentos. Mientras la prescripción extingue la responsabilidad penal, la prescripción gradual confiere al juez un poder discrecional para atenuar la pena, atendida la remisión del artículo 103 a los artículos 65, 66, 67 y 68 del Código Penal25.

21 Para una reseña esquemática de las teorías existentes, vid. GUZMÁN DÁLBORA, J. L. La Extinción de la Responsabilidad Penal. En: POLITOFF, S. y ORTIZ, L. (dir.); MATUS, J. P. (coord): Texto y comentario del Código Penal chileno, Santiago, Editorial Jurídica de Chile, 2002, pp. 460 y ss.; RIGHI, E. Los límites de la Persecución Penal y la tutela de Derechos Fundamentales, Cuadernos de Doctrina y Jurisprudencia Penal, 2 (3), Buenos Aires, Ad-hoc, 1996, pp. 192 y ss.; YUSSEF SOTOMAYOR, G., La Prescripción Penal. $3^{\mathrm{a}}$ ed., Santiago, Editorial Jurídica de Chile, 2005, pp. 43 y ss. y 59 y ss; RAGUÉS I. VALLÈS, R. La Prescripción Penal: Fundamento y Aplicación, Barcelona, Atelier, 2004, pp. 21 y ss.

22 Una manera de enfocar el problema sería realizar un análisis crítico de las diferentes teorías esbozadas sobre el fundamento de la prescripción y reflexionar sobre su eventual compatibilidad con la prescripción gradual; sin embargo, los límites espaciales de este comentario no nos permiten abordar un estudio de semejante naturaleza.

23 GUZMÁN DÁLBORA, J. L., Op. cit., p. 483.

24 Sentencias de reemplazo "Episodios Parral y Liquiñe", considerandos 20 y 17 respectivamente.

25 La doctrina es ampliamente mayoritaria respecto a la discrecionalidad. Vid. DÍAZ CRUZAT, A. Apuntes sobre algunos problemas que plantean los artículos 96 y 103 del Código Penal y su relación con la Prescripción. Gaceta Jurídica 211, Santiago, 1998, pp. 23 y 24; YUSSEF SOTOMAYOR, Op. cit., p. 163; VARGAS VIANCOS, J. E. La Extinción de la Responsabilidad Penal. $2^{\text {a }}$ ed., Santiago, Editorial Jurídica Conosur Ltda., 1994, pp. 198 y 199, con cita de jurisprudencia; NOVOA MONREAL, E. Curso de Derecho Penal Chileno, 2 vols., $3^{a}$ ed., Santiago, Editorial Jurídica de Chile, 2005, t. II, p. 414. En contra GUZMÁN DÁLBORA, Op. cit., p. 484. Abstrayéndonos de la postura sostenida en este comentario e imaginándonos una hipotética aplicación de la prescripción gradual en casos de violación a los derechos humanos, cabe preguntarse legítimamente acerca de los factores que debería tomar en cuenta el juez para medir su poder facultativo. Creemos que la discrecionalidad debe ser orientada por el grado de injusto del hecho y de culpabilidad del autor. Parece ser evidente que la violación grosera de derechos tan importantes, consecuencia de delitos cometidos sistemática y 
La Corte Suprema en fallos anteriores ha afirmado que los delitos cometidos en casos de derechos humanos durante la dictadura son imprescriptibles. Para estos efectos ha aplicado los Convenios de Ginebra, considerando que en la época de comisión de los ilícitos el Estado de Chile se encontraba en "estado o tiempo de guerra" 26 . Igualmente, ha indicado que estos Convenios, conforme lo dispuesto en el inciso segundo del artículo $5^{\circ}$ de la Carta Fundamental, tienen aplicación preeminente, de modo que omitir su aplicación importa un error de Derecho, y que constituye un deber del Estado adecuar su normativa interna al Derecho internacional que garantiza los derechos esenciales que emanan de la naturaleza humana ${ }^{27}$.

La prohibición de formas de autoexoneración, tales como la amnistía y la prescripción, también ha sido fundamentada en reglas imperativas del Derecho internacional o ius cogens, es decir, normas superiores del Derecho internacional que no admiten derogación alguna, salvo por otras normas del mismo carácter y que el Estado chileno no puede desconocer bajo ninguna circunstancia ${ }^{28}$.

Estimamos que el ámbito normativo de los efectos de la imprescriptibilidad cubre los fundamentos y reglas de ejecución de la prescripción, entre ellas, las que regulan la prescripción gradual. En efecto, si el carácter imprescriptible de los delitos de esta naturaleza habilita la persecución y penalización de los autores sin consideración de límites cronológicos, pierde sentido conceder los beneficios derivados de la prescripción gradual, toda vez que la esencia de ésta reside en estar sometida a límites de tiempo.

\section{b. Cómputo del plazo de la prescripción gradual y el carácter de ejecución permanente del delito de secuestro}

La doctrina nacional califica, unánimemente, el delito de secuestro como un delito permanente ${ }^{29}$, opinión aceptada por la jurisprudencia comentada ${ }^{30}$. Esta categoría de ilícito penal se caracteriza

reiteradamente por agentes estatales, debe influir necesariamente en la discrecionalidad del juicio valorativo, terminando por deshabilitar la facultatividad del juzgador o por reducirla a una dimensión irrisoria. Por lo demás, este criterio fue el que sostuvo la Corte Suprema en el proceso por el homicidio de Orlando Letelier (Sentencia de 30 de mayo de 1995, considerando $24^{\circ}$ ).

26 Vid. QUEZADA CABRERA, H. Informe en Derecho sobre el Estado de Guerra en Chile y la aplicación de los Convenios de Ginebra, Santiago, 2004.

27 Cfr. las siguientes sentencias de la Corte Suprema: 9 septiembre 1998, Rol № 469-98, por la desaparición de Pedro Poblete Córdova, considerandos $9^{\circ}$ y $10^{\circ} ; 17$ noviembre 2004, Rol № 517-04, por la desaparición de Miguel Ángel Sandoval Rodríguez, considerando 33; 18 enero 2007, Rol № 2666-04, por el homicidio calificado de José Matías Ñanco, considerando $12^{\circ} ; 13$ marzo 2007, Rol № 3125-04, por el homicidio de Manuel Tomás Rojas, considerando $16^{\circ}$; 10 mayo 2005, Rol No 3452-06, por el secuestro calificado de Ricardo Troncoso Muñoz y otros, considerandos $39^{\circ}$ y $40^{\circ}$.

28 Cfr. las siguientes sentencias de la Corte Suprema: 13 diciembre 2006, Rol № 559-04, por los homicidios de Hugo Vásquez Martínez y Mario Superby Jeldres, considerando 26; caso Matías Ñanco, cit., considerando $17^{\circ}$; caso Troncoso Muñoz y otros, cit., considerando 58 ; 13 noviembre 2007, Rol № 6188-06, por el secuestro calificado de Carlos Humberto Contreras Maluje, considerando 28; 24 enero 2008, Rol № 1528-06, por el secuestro y ejecución de Gabriel Marfull

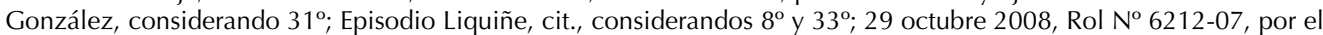
secuestro de Ofelio de la Cruz Lazo Lazo, considerando $24^{\circ}$ y citado como fundamento de la imprescriptibilidad en sentencia de 24 diciembre 2008, Rol № 1013-08, por los secuestros de Carmen Margarita Díaz Darricarrere e Iván Eugenio Montti Cordero, considerando $1^{\circ}$.

29 LABATUT GLENA, G. Derecho Penal. 2 vols., $9^{a}$ ed. (actualizada por el prof. Julio Zenteno Vargas), Santiago, Editorial Jurídica de Chile, t. I, 1995, p. 165; ETCHEBERRY, A. Derecho Penal. 4 vols., $3^{\text {a }}$ ed. revisada y actualizada, Santiago, Editorial Jurídica de Chile, 1998, t. III, p. 205; GARRIDO MONTT, M. Derecho Penal. 4 vols., $3^{\text {a }}$ ed., Santiago, Editorial Jurídica de Chile, 1997, t. II, p. 259; POLITOFF LIFSCHITZ, S. y MATUS ACUÑA, J. P., RAMÍREZ, M. C. Lecciones de Derecho Penal Chileno. Parte especial, $2^{a}$ ed., Santiago, Editorial Jurídica de Chile, 2005, p. 201; HERNÁNDEZ, H. El secuestro como delito permanente. Precisiones para la reflexión política. Mensaje, 1 de julio de 2004; NOVOA MONREAL, E., Op. cit., t. I, p. 249.

30 Sentencias de reemplazo del "Episodio Parral", cit., considerando $9^{\circ}$ y del Episodio Liquiñe, cit., considerando 20 y voto de minoría del ministro Künsemüller. 
por el mantenimiento del estado antijurídico o por la prolongación temporal del período consumativo $^{31}$. Por tanto, sólo puede configurarse respecto de bienes jurídicos que no sean susceptibles de ser destruidos o disminuidos, sino sólo obstaculizados en su ejercicio o goce ${ }^{32}$.

La Corte, al aplicar la prescripción gradual, ha debido enfrentar el problema de determinar el parámetro para computar el plazo atendido el carácter peculiar de estos delitos, una de cuyas consecuencias consiste, precisamente, en que el inicio del cómputo del plazo de la prescripción coincide con la terminación del delito. La discusión se torna estéril si se parte de la premisa de la imprescriptibilidad o del hecho de que, tal como ha dado a entender la Corte Suprema en algunas sentencias, se han catalogado los secuestros cometidos en dictadura como desaparición forzada de personas ${ }^{33}$. Por tanto, no es concebible que el plazo corra a favor de los imputados y, por ende, no corresponde determinar el inicio de un término inexistente.

A mayor abundamiento, en el secuestro la lesión del bien jurídico consiste en la privación de libertad de la víctima, por lo que el inicio del cómputo del plazo puede ser determinado en la medida en que se acredite la recuperación de la libertad o el fallecimiento de la víctima. Frente a la inexistencia de prueba de tales hechos -por tratarse de detenidos desaparecidos respecto de los cuales se perdió todo rastro y cuyos restos no han sido hallados-, el delito sigue siendo permanente volviéndose imposible determinar el inicio del cómputo ${ }^{34}$.

Tal como se ha señalado en la sentencia sobre el "Episodio Parral", nuestro máximo tribunal estimó que, siendo el secuestro calificado un delito permanente, "la consumación se ha producido al prolongarse el encierro por más de noventa días [contándose el plazo] a partir de esa fecha, es decir, a contar del día noventa y dos" ${ }^{\prime 35}$. Por su parte, el fallo sobre el "Episodio Liquiñe" toma como punto de partida la autoría mediata por el dominio de la voluntad mediante un aparato organizado de poder que se le atribuyó al acusado, para luego concluir que ese dominio, necesariamente, termina al momento en que el imputado se acoge a retiro del ejército, ocurrido el 31 de mayo de 1981, siendo ésta la fecha que debe tomarse en cuenta para el inicio del cómputo del plazo. La Corte, además, refuerza su argumento señalando que han transcurrido más de dieciocho años desde la reinstalación del estado de Derecho democrático en el país, tiempo más que suficiente para superar el margen establecido en el Código Penal para la configuración de la prescripción gradual ${ }^{36}$.

31 De RIVACOBA y RIVACOBA, M. El delito de Usurpación y el problema de su Prescripción. Gaceta Jurídica 48, 1984, Santiago, pp. 3 y 4.

32 BETTIOL, G. y PETTOELLO MANTOVANI, L. Diritto penale, $12^{\text {a }}$ ed. riveduta e integrata, Padova, Cedam, 1986, pp. 607 y ss.

33 Cfr. sentencias de la Corte Suprema del caso Sandoval Rodríguez, cit., considerando $32^{\circ}$ y 11 octubre 2007 , Rol N ${ }^{\circ} 2370$ 07, por el secuestro de Nelson Llanquilef Velásquez, considerando $5^{\circ}$.

34 Cfr. sentencias de la Corte Suprema caso Sandoval Rodríguez, cit., considerando $39^{\circ}$ y 30 mayo 2006, Rol № 3215-05, por el secuestro de Diana Frida Arón Svigilsky, considerando 6º También, De RIVACOBA y RIVACOBA, M. Alegato para desaforar al Senador Vitalicio Augusto Pinochet Ugarte. En su: Violencia y Justicia, Valparaíso, Universidad de Valparaíso, 2002, p. 150.

35 Considerando $26^{\circ}$.

36 GUZMÁN DÁLBORA, J. L. Crímenes Internacionales y Prescripción. En: Ambos, K., Malarino, E. y Woischnick, J. (eds), Temas actuales de Derecho Penal Internacional. Contribución de América Latina, Alemania y España. Montevideo, Konrad Adenauer-Stiftung, 2005, pp. 103-115 y HORVITZ LENNON, M. I., Amnistía y Prescripción en causas sobre Violación a los Derechos Humanos en Chile. Anuario de Derechos Humanos 2, 2006, Santiago, Centro de Derechos Humanos, Facultad de Derecho Universidad de Chile, pp. 224 y 225. Ambos, si bien con ciertos matices en la fundamentación, han sostenido la idea de que el plazo de prescripción permanece suspendido hasta ese momento. Sin embargo, la Corte sólo de manera indirecta se refiere a esta idea, ocupándolo como argumento de añadidura, basando la centralidad de su discurso en la individualización del momento en que concluye el dominio del hecho. 
Creemos que los antecedentes que el sentenciador invoca en estas sentencias para identificar el inicio del cómputo del plazo de la media prescripción responden a consideraciones antojadizas que se utilizan para la construcción de presunciones fundadas en meras abstracciones, siendo, por lo demás, ajenas a la prueba rendida. El problema es bien procesal más que penal, ya que demostrada la privación de libertad de la víctima, pero no su muerte o la recuperación de su libertad, se entiende que el término del período consumativo tampoco ha sido probado de manera objetiva, faltando un presupuesto legal para la procedencia de la prescripción gradual ${ }^{37}$. Lo determinante es el mantenimiento del estado antijurídico y no el dominio del aparato de poder, lo que sólo resulta relevante para la configuración de la autoría mediata.

\section{c. Obligaciones internacionales incumplidas}

La Corte Suprema, al relativizar el carácter imprescriptible de los graves crímenes investigados y determinar forzadamente su consumación con el único objeto de aplicar la prescripción gradual, no sólo comete errores de argumentación en los que desconoce elementos esenciales de las diversas instituciones del Derecho penal e internacional involucradas, sino que infringe diversas obligaciones internacionales, dejando expuesto al Estado de Chile a sanciones jurídicas en el marco del sistema interamericano de protección de los derechos humanos.

La Convención Americana sobre Derechos Humanos establece en su artículo $1^{\circ}$ dos importantes obligaciones para los Estados partes: respetar los derechos humanos y garantizar su ejercicio y goce de todas las personas sujetas a su jurisdicción. La obligación de respetar exige que ni el Estado, ni sus agentes, ni terceros actuando con la aquiescencia o tolerancia del Estado, violen los derechos humanos establecidos en la Convención. La obligación de garantizar exige al Estado emprender las acciones necesarias para asegurar que todas las personas sujetas a su jurisdicción estén en condiciones de ejercerlos y gozarlos ${ }^{38}$. Respecto de esta última, la Corte Interamericana de Derechos Humanos ha señalado en forma reiterada que: "[..] como consecuencia de esta obligación los Estados deben prevenir, investigar y sancionar toda violación de los derechos reconocidos por la Convención y procurar, además, el restablecimiento, si es posible, del derecho conculcado y, en su caso, la reparación de los daños producidos por la violación de los derechos humanos. Si el aparato del Estado actúa de modo que tal violación quede impune y no se restablezca, en cuanto sea posible, a la víctima en la plenitud de sus derechos, puede afirmarse que ha incumplido el deber de garantizar su libre y pleno ejercicio a las personas sujetas a su jurisdicción" ${ }^{\prime 39}$.

La Corte Interamericana en la sentencia del caso Almonacid le indicó al Estado de Chile que no podrá argüir ninguna ley ni disposición de Derecho interno para eximirse de cumplir con lo dispuesto en el fallo: investigar y sancionar penalmente a los responsables de crímenes de lesa humanidad ${ }^{40}$. La Corte Suprema hace caso omiso de la obligación del Estado de sancionar cuando aplica la prescripción gradual en beneficio de los responsables de delitos de lesa humanidad y los deja en libertad.

El Derecho internacional nos da ciertas luces sobre los requisitos de la pena, los que a nuestro juicio no se satisfacen con la aplicación de la prescripción gradual. Estos son:

\footnotetext{
37 Vid. voto de prevención del ministro Künsemüller, cit.

38 MEDINA QUIROGA, C. y NASH ROJAS, C. Sistema Interamericano de Derechos Humanos. Introducción a sus Mecanismos de Protección. Santiago, Centro de Derechos Humanos, Facultad de Derecho Universidad de Chile, 2007, p. 19.

39 Corte IDH, caso Almonacid Arellano, sentencia de 26 septiembre de 2006, serie C, № 154, párrafo 110. Énfasis añadido.

40 Corte IDH, caso Almonacid Arellano, cit., párrafos 152 y 153.
} 
i. Fines de la pena en el sistema de protección de los derechos humanos

La Asamblea General de las Naciones Unidas en su resolución 2583 (XXIV) de 15 de diciembre de 1969 señaló respecto de los delitos de lesa humanidad que la sanción de los responsables por tales delitos "es un elemento importante para prevenir esos crímenes y proteger los derechos humanos y las libertades fundamentales, y para fomentar la confianza, estimular la cooperación entre pueblos y contribuir a la paz y la seguridad internacionales". La pena y su imposición resguardan y refuerzan, en el presente y hacia el futuro, el respeto de los ciudadanos por los valores elementales sobre los que descansa la posibilidad de una convivencia pacífica (prevención general positiva) y disuade a quienes se sientan inclinados a incurrir en hechos semejantes (prevención general negativa) ${ }^{41}$. Además, una sanción adecuada a la gravedad del delito es parte de una reparación integral que involucra, a lo menos, una investigación conducente a revelar la verdad sobre los hechos $y$, por sobre todo, un esfuerzo por parte del Estado de castigar penal y disciplinariamente a quienes resultaren responsables ${ }^{42}$.

\section{ii. Proporcionalidad de la pena}

La Corte Interamericana de Derechos Humanos afirma que el Estado satisface el deber de garantizar adecuadamente los diversos derechos protegidos en la Convención cuando observa el principio de proporcionalidad de la pena. La Corte ha especificado esta obligación de la siguiente forma: "[e]n cuanto al referido principio de proporcionalidad de la pena, la Corte estima oportuno resaltar que la respuesta que el Estado atribuye a la conducta ilícita del autor de la transgresión debe ser proporcional al bien jurídico afectado y a la culpabilidad con la que actuó el autor, por lo que se debe establecer en función de la diversa naturaleza y gravedad de los hechos" ${ }^{\prime 3}$. Agrega que todos los elementos que incidan en la efectividad de la pena deben responder a un objetivo claramente verificable y ser compatible con la Convención ${ }^{44}$.

\section{iii. La pertinencia de la pena}

Pertinencia es el estándar exigido por el sistema de protección internacional de derechos humanos, según el cual la envergadura del castigo debe servir para cumplir con los fines que ya hemos especificado y con la proporcionalidad necesaria. Adicionalmente, la Comisión y la Corte Interamericana asocian este estándar a la obligación contenida en el 1.1. de la Convención. A modo de ejemplo, la Comisión ha argumentado que "de conformidad con las reglas del Derecho Internacional y la jurisprudencia de esta Corte, la acción u omisión de cualquier autoridad pública compromete la responsabilidad del Estado respecto de los artículos de la Convención y éste está en la obligación de identificar a los responsables de las acciones u omisiones e imponerles las sanciones pertinentes" ${ }^{\prime 4}$. Del mismo modo, en diversos informes ha precisado que las sanciones pertinentes son las adecuadas según la gravedad de las violaciones ${ }^{46}$. Por su parte, la Corte

41 Considerando $4^{\circ}$ del voto de minoría de los ministros Cury y Rodríguez, en el fallo pronunciado por la desaparición de Ricardo Rioseco Montoya y Luis Cotal Álvarez, sentencia de la Corte Suprema de 4 agosto 2005, Rol № 457-05.

42 MÉNDEZ, J. E. Derecho a la Verdad frente a las graves Violaciones a los Derechos Humanos. En: ABREGU, M. y COURTIS, Ch. (coomp). La aplicación de los Tratados sobre Derechos Humanos por los tribunales locales, Buenos Aires, Centro de Estudios legales y Sociales, Editores del puerto, 1997, p. 525.

43 Corte IDH, caso de la Masacre de la Rochela. Sentencia 11 de mayo de 2007, Serie C № 163, párrafo Párr. 196.

44 Ídem.

45 Corte IDH, caso del Tribunal Constitucional vs. Perú. Sentencia 31 de enero de 2001. Serie C No 71 párr. 105 letra a).

46 Informe № 23/01, del 5 marzo de 2002. 
interamericana ha señalado que el Estado tiene el deber jurídico de imponerles las sanciones pertinentes y de asegurar a la víctima una reparación adecuada ${ }^{47}$.

\section{Conclusión}

Estimamos que la aplicación de la prescripción gradual en casos de violaciones a los derechos humanos debe ser rechazada. En los casos antes referidos, la Corte Suprema no motiva correctamente sus sentencias, descuida aspectos dogmáticos y procesales, e incurre en incongruencias argumentativas en el afán de aplicar una institución cuyo diseño histórico-legislativo fue pensado para otras realidades, y cuya aplicación en casos de derechos humanos resulta forzada. Además, aunque la jurisprudencia citada evidencia la evolución de nuestro tribunal superior, pues éste reconoce explícitamente que el Derecho internacional es una fuente directa de obligaciones internacionales para el Estado de Chile en lo referido al respeto de los derechos humanos, dicha evolución ha sufrido serios tropiezos y contradicciones a causa de los fallos del último bienio. Al aplicar la prescripción gradual a delitos de lesa humanidad, la Corte Suprema, finalmente, compromete la responsabilidad internacional del Estado por el incumplimiento de sus obligaciones internacionales, particularmente respecto de la Convención Americana sobre Derechos Humanos.

47 Corte IDH, caso Velásquez Rodríguez. Sentencia 26 de junio de 1987, Serie C No 1, párrafo 174, y caso Godínez Cruz, Sentencia 26 de junio de 1987, Serie C No 3, párrafo 184. CIDH, caso La Cantuta, Sentencia 29 de noviembre de 2006, Serie C No 162 , párrafo 224 . 